\title{
Removal of Toxic Pollutants from Aqueous Solutions by Adsorption onto Organo-kaolin
}

\author{
S.A. Sayed Ahmed ${ }^{\wedge}$ \\ Department of physical Chemistry, National Research Centre, Dokki, Cairo, Egypt \\ ^e-mail: sohairabdelaziz@yahoo.com \\ (Received October 13, 2009; Accepted December 4, 2009)
}

\begin{abstract}
In this study, the adsorption of toxic pollutants onto cetyltrimethylammonium kaolin (CTAB-Kaolin) is investigated. The organo-kaolin is synthesized by exchanging cetyltrimethylammonium cations (CTAB) with inorganic ions on the surface of kaolin. The chemical analysis, the structural and textural properties of kaolin and CTAB-kaolin were investigated using elemental analysis, FTIR, SEM and adsorption of nitrogen at $-196^{\circ} \mathrm{C}$. The kinetic adsorption and adsorption capacity of the organo-kaolin towards $o$-xylene, phenol and $\mathrm{Cu}$ (II) ion from aqueous solution was investigated. The kinetic adsorption data of $o$-xylene, phenol and $\mathrm{Cu}(\mathrm{II})$ are in agreement with a second order model. The equilibrium adsorption data were found to fit Langmuir equation. The uptake of $o$-xylene and phenol from their aqueous solution by kaolin, CTAB-kaolin and activated carbon proceed via physisorption. The removal of $\mathrm{Cu}(\mathrm{II})$ ion from water depends on the surface properties of the adsorbent. Onto kaolin, the $\mathrm{Cu}$ (II) ions are adsorbed through cation exchange with $\mathrm{Na}^{+}$. For $\mathrm{CTAB}-\mathrm{kaolin}, \mathrm{Cu}(\mathrm{II})$ ions are mainly adsorbed via electrostatic attraction with the counter ions in the electric double layer $\left(\mathrm{Br}^{-}\right)$, via ion pairing, $\mathrm{Cu}(\mathrm{II})$ ions removal by the activated carbon is probably related to the carbon-oxygen groups particularly those of acid type. The adsorption capacities of CTAB-kaolin for the investigated adsorbates are considerably higher compared with those of unmodified kaolin. However, the adsorption capacities of the activated carbons are by far higher than those determined for CTAB-kaolin.
\end{abstract}

Keywords : Organo-kaolin, Phenol, o-xylene, Cu(II), Adsorption, Kinetics

\section{Introduction}

Organo-clays are engineered sorbents synthesized by modifying the surface nature of natural clays. Such modification is frequently achieved by sorbing a cationic surfactant onto the external surface and into the interlayer spacing of the clays [1-3]. The clay surface changes from hydrophilic to hydrophobic and from negatively to positively charge. Hence, the organo-clay surface is organophilic and displays an anion-exchange capacity. The sorption of a cationic surfactant onto the surface of the natural clay is mainly governed by cation exchange and hydrophobic interactions [4], being dependent on the principle group size and the surfactant concentration [3]. Moreover, the nature of and charge on the organo-clay surface are dependent on the surfactant loading [5].

In several works, hexa-decyltrimethylammonium bromide (HDTMA) has been used as surfactant for modifying the surface of natural clays and zeolites $[1,2,6]$.

The removal of organic compounds or toxic metal ions contaminants has received considerable attention in recent years. $o$-Xylene, phenol and $\mathrm{Cu}(\mathrm{II})$ ions are very toxic and accumulate in the human body even at low concentration. As a result, there has been a growing interest in the development and implementation of various adsorbents for the removal of specific organic substances from water. In this respect, organo-clays have been widely studied because they are cheaper than other sorbents such as activated carbons and resins [3,7-10].

Several methods exist for the treatment of metalcontaminated effluent, viz. precipitation, ion exchange and adsorption. Adsorption is one of the more popular methods for the removal of heavy metals or organic compounds from waste water.

Other authors [1,2,11-14] have investigated the adsorption of organic compounds such as penta-chlorophenol, phenol, chlorobenzene and acid dyes onto montmorillonite and bentonite clays modified with cationic surfactants. They showed that modification of the clay increased the adsorption capacity.

Many surfactant-modified clays have been investigated with bentonite receiving the greatest attention. Literature surveying revealed that very few studies have been devoted to modify the surface properties of kaolin with surfactants. Egypt among other countries is rich in kaolin deposits. The present investigation aimed at the characterization of the textural properties of one of the Egyptian kaolin deposits and to investigate its adsorption capacities particularly towards 
the removal of hazardous material from water. One of the objects of this investigation is to determine the change of the sorption capacity of the kaolin upon surface modification with $\mathrm{CTAB}$ as a representative cationic surfactant. $o$-Xylene and phenol were selected as organic pollutants in water and $\mathrm{Cu}$ (II) ion as inorganic pollutant.

\section{Experimental}

\subsection{Materials}

The starting clay used in this study is a local Egyptian sample. The kaolin was lightly ground and sieved. Fine particles with a diameter $<150 \mu \mathrm{m}$ were used in subsequent experiments. The mineralogical composition of the kaolin indicates that it consisted mainly of kaolin (Ca. 95\%) with minor components mainly quartz and Feldspar. Its chemical compositions (in wt $\%$ ) as determined by $\mathrm{x}$-ray fluorescence was $\mathrm{SiO}_{2}, 47.23 ; \mathrm{Al}_{2} \mathrm{O}_{3}, 36.5 ; \mathrm{Fe}_{2} \mathrm{O}_{3}, 0.60 ; \mathrm{TiO}_{2}, 0.80 ; \mathrm{CaO}$, $0.40 ; \mathrm{MgO}, 0.04 ; \mathrm{K}_{2} \mathrm{O}, 0.37 ; \mathrm{Na}_{2} \mathrm{O}, 0.06 ; \mathrm{H}_{2} \mathrm{O}$ (weight loss during calcinations), 10.8 .

The $\mathrm{Na}^{+}$- exchanged form of clay was prepared by stirring samples of the latter for $24 \mathrm{~h}$ with $1 \mathrm{~N} \mathrm{NaCl}$. This was followed by several washings with distilled water and centrifuged cycles to remove the excess $\mathrm{NaCl}$ and other exchangeable cations from the clay. The clay was then resuspended and centrifuged until a negative chloride test was obtained with $0.1 \mathrm{M} \mathrm{AgNO}_{3}$.

Prior to the preparation of the organo-clay, the cation exchange capacity (CEC) was determined to be 40 meq./ $100 \mathrm{mg}$ kaolin. The Na-saturated clay $(50 \mathrm{~g})$ was dispersed in $1 \mathrm{~L}$ of distilled water. Cetyltrimethyl Ammonium Bromide (CTAB)-kaolin was prepared by adding an amount of CTAB equals 4-fold the $\mathrm{CEC}$ value of kaolin. The solution mixture was centrifuged and the solid was washed five times with distilled water to remove the CTAB excess.

A commercial granular activated carbon, AC, was used as adsorbent in this study. This activated carbon was kindly supplied by Norit via the chemical activation of peanut shells with phosphoric acid. This carbon was chosen because it has been widely investigated both for the adsorption of organic compounds and metallic cations.

The toxic organic pollutants studied were $o$-xylene (BDH), phenol (Analytical Rasayan) and inorganic toxic cation $\mathrm{Cu}$ (II) ions from $\mathrm{CuSO}_{4} \cdot 5 \mathrm{H}_{2} \mathrm{O}$ (Fluka). Other reagents used are of analytical grade and used without further purification.

\subsection{Techniques}

Cation exchange capacity (CEC) studies were under taken to obtain information about the total amount of exchangeable cations that can be bound by the sorption. To measure this, the relevant functional groups on the sorbent were first protonated with hydrochloric acid. This was followed by filtration and washing with distilled water till free of acid, the sorbent was placed in a barium acetate solution where the exchangeable protons. The released protons were then titrated with standard sodium hydroxide in the presence of an indicator. The CEC results were expressed as (meq/100 g).

The textural properties were determined on degassed samples at $200^{\circ} \mathrm{C}$ for $6 \mathrm{~h}$ under a reduced pressure of $10^{-5}$ Torr by nitrogen adsorption at $77 \mathrm{~K}$ using conventional volumetric apparatus. FTIR spectra of the inorganic and organic- kaolin were recorded using Mattson 1000 FTIR spectrophotometer. The morphologies of the individual kaolin and organo-kaolin particle surfaces were observed by using scanning electron microscopy (SEM) with a JEOLJSM (magnification 2200X). The $\mathrm{pH}$ value of each solution was measured periodically and kept constant by adding 0.01 $\mathrm{HNO}_{3}$ or $\mathrm{NaOH}$ solution as required.

The kinetic adsorption of $o$-xylene, phenol or $\mathrm{Cu}(\mathrm{II})$ ions by investigated adsorbents at $303 \mathrm{~K}$ was undertaken by determining the amount adsorbed per one gram adsorbent at different intervals of time. The equilibrium adsorption was undertaken using the batch shaking technique at $303 \mathrm{~K}$. All experiments were conducted in duplicate to ensure reproducibility.

After a definite time interval or equilibrium time, the concentration of $o$-xylene and phenol was analyzed spectrophotometrically to determine the amount adsorbed, the absorbancies of $o$-xylene and phenol were followed at $269 \mathrm{~nm}$ and $270 \mathrm{~nm}$, respectively. The individual standard was dissolved in ethanol and diluted with distilled water to obtain solutions with concentrations range $10 \sim 50 \mathrm{mg} / \mathrm{l}$. A stock solution of $\mathrm{Cu}(\mathrm{II})$ ions $(0.25 \mathrm{M})$ was prepared by dissolving $\mathrm{CuSO}_{4} .5 \mathrm{H}_{2} \mathrm{O}$ in distilled water. The $\mathrm{Cu}(\mathrm{II})$ ions concentration in aqueous solution was determined using varian spectra AA-200 atomic absorption spectrophotometer (AAS) in flame mode with an air-acetylene flame at the corresponding maximum absorption wavelength $213.9 \mathrm{~nm}$ for $\mathrm{Cu}(\mathrm{II})$ ions.

\section{Results and Discussion}

The textural properties (surface area and porosity) of an adsorbent are important parameters in determining its adsorption capacity as well as its adsorption performance [15]. The adsorption isotherms thus obtained (not illustrated) were analysed using the conventional BET equation. Table 1 lists the surface areas, total pore volumes and mean pore diameters of kaolin, organo-kaolin and activated carbon. Table 1 reveals that (i) the surface area and total pore volume of the activated carbon are higher whereas its mean pore diameter is lower compared with the corresponding parameters of kaolin and organo-kaolin. (ii) Modification of kaolin with (CTAB) was found to be associated with a decrease in the surface area and total pore volume, but with 
Table 1. Textural Properties of Kaolin, Organo-kaolin and Activated Carbon

\begin{tabular}{cccc}
\hline Adsorbent & $\begin{array}{c}\text { Surface area } \\
\left(\mathrm{m}^{2} / \mathrm{g}\right)\end{array}$ & $\begin{array}{c}\text { Pore volume } \\
\left(\mathrm{cm}^{3} / \mathrm{g}\right)\end{array}$ & $\begin{array}{c}\text { Average pore } \\
\text { diameter }(\mathrm{nm})\end{array}$ \\
\hline Kaolin & 24.2 & 0.0351 & 5.8 \\
\hline Organo-kaolin & 7.5 & 0.0170 & 9.0 \\
\hline $\begin{array}{c}\text { Activated } \\
\text { carbon }\end{array}$ & 808.6 & 0.271 & 1.34 \\
\hline
\end{tabular}

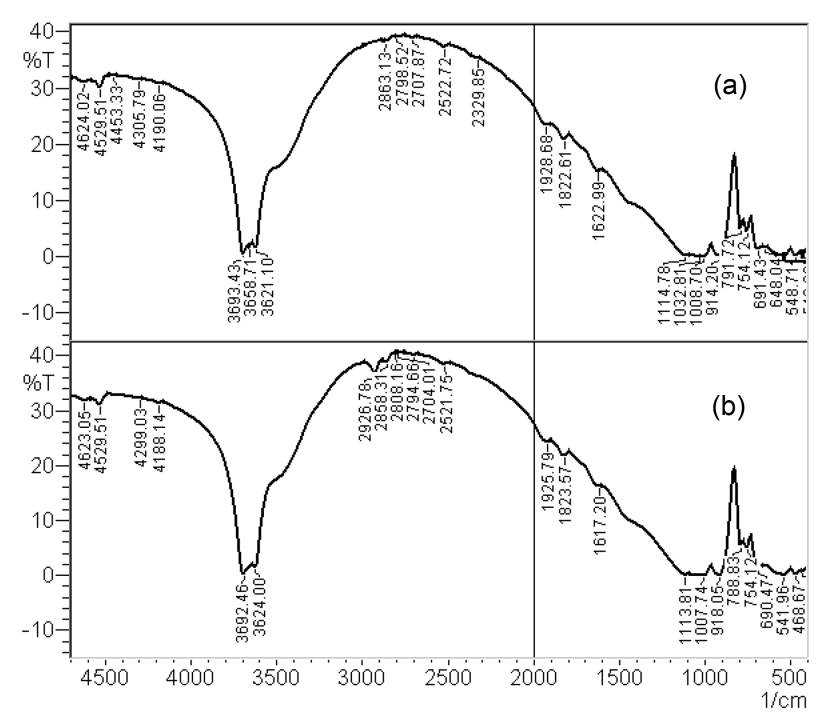

Fig. 1. FTIR spectra of the (a) natural kaolin and (b) organokaolin.

an increase in the mean diameter. These textural changes are depicted when the textural properties of kaolin are compared with those of organo-kaolin. (iii) The pronounced changes in the textural parameters brought about by modifying kaolin with this cationic surfactant may be ascribed to the blocking of relatively narrow pores by the surfactant molecules leaving behind the relatively wide pores [16].

To obtain evidence for the adsorption of CTAB cations into kaolin sample, FTIR spectra were recorded over the spectral region $400 \sim 4000 \mathrm{~cm}^{-1}$ shown in Fig. 1. A pair of strong bands at 2858 and $2926 \mathrm{~cm}^{-1}$ which were observed with the surfactant modified kaolin could be assigned to the symmetric and asymmetric stretching vibrations of the methylene and methyl group $\mathrm{CH}_{2}, \mathrm{CH}_{3}$ of the aliphatic chain of the surfactant. This band is not observed in the IR spectrum of natural kaolin.

Modification of kaolin with CTAB was associated also with pronounced change in the particle size and morphology. The scanning electron microscope (SEM) images of kaolin and organo-kaolin are shown in Figs. 2 and 3, respectively. Evidently, the agglomerates of kaolin consist of few numbers of particles compared with those of organo-kaolin. Some of the particles in kaolin and organo-kaolin show laminar crystalline habit characteristic of phyllosilicates. However, these particular particles dominate more in organo-kaolin.

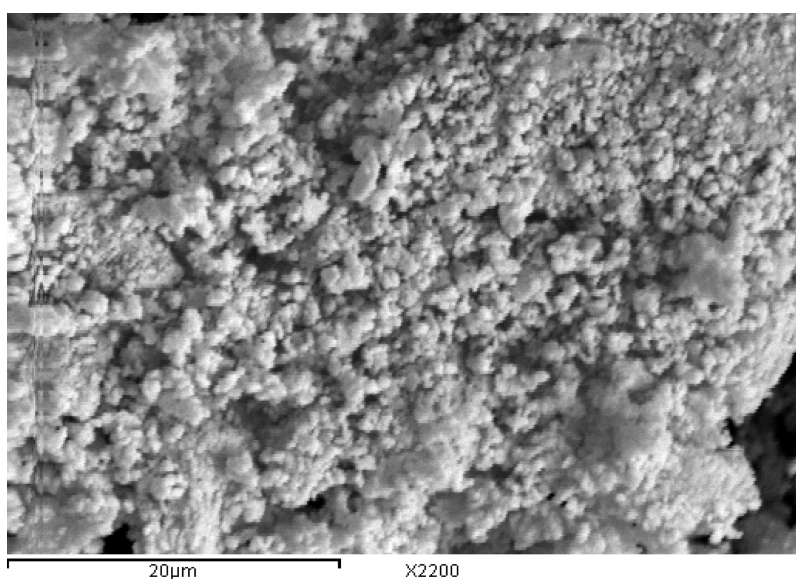

Fig. 2. SEM micrographs of kaolin.

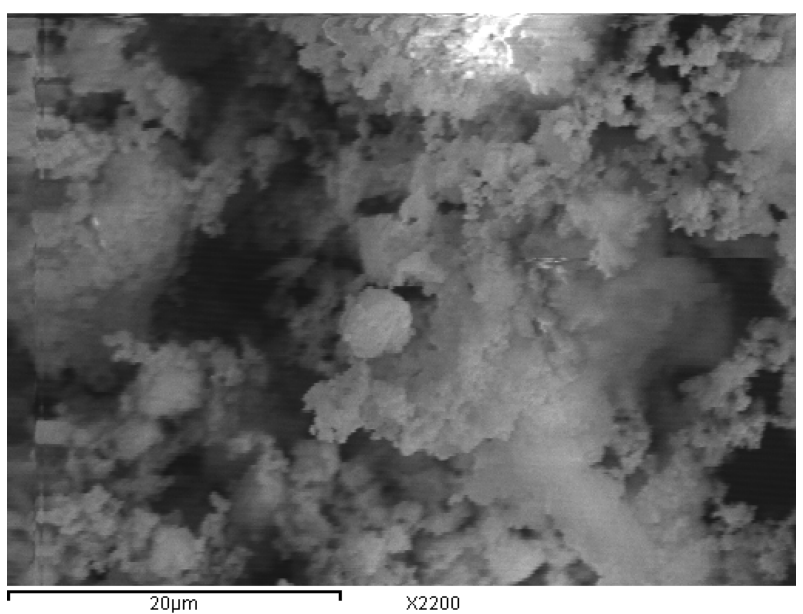

Fig. 3. SEM micrographs of organo-kaolin.

Interaction of surfactant molecules within the interlayers may also stand behind the domination of relatively large agglomerates and large laminar crystallites.

\subsection{Kinetic study}

The kinetic experiments on the adsorption from aqueous solution are important to decide the order of the reaction, its rate constant as well as to determine the equilibrium time that should be allowed to study the equilibrium adsorption. One and the same initial concentration of an adsorbate was used for its adsorption onto the sorbents investigated. Thus, an initial concentration of $200 \mathrm{mg} / \mathrm{L}$ was used for $o$-xylene and phenol whereas $100 \mathrm{mg} / \mathrm{L}$ was the initial concentration of $\mathrm{Cu}$ (II) ions.

The kinetic adsorption curves of $o$-xylene, phenol and $\mathrm{Cu}(\mathrm{II})$ at $303 \mathrm{~K}$ and $\mathrm{pH} 6.0$ are shown in Fig. 4(a,b and c), respectively.

Fig. 4 depicted that (i) activated carbon exhibited the highest adsorption capacity for all adsorbates. (1) As- 

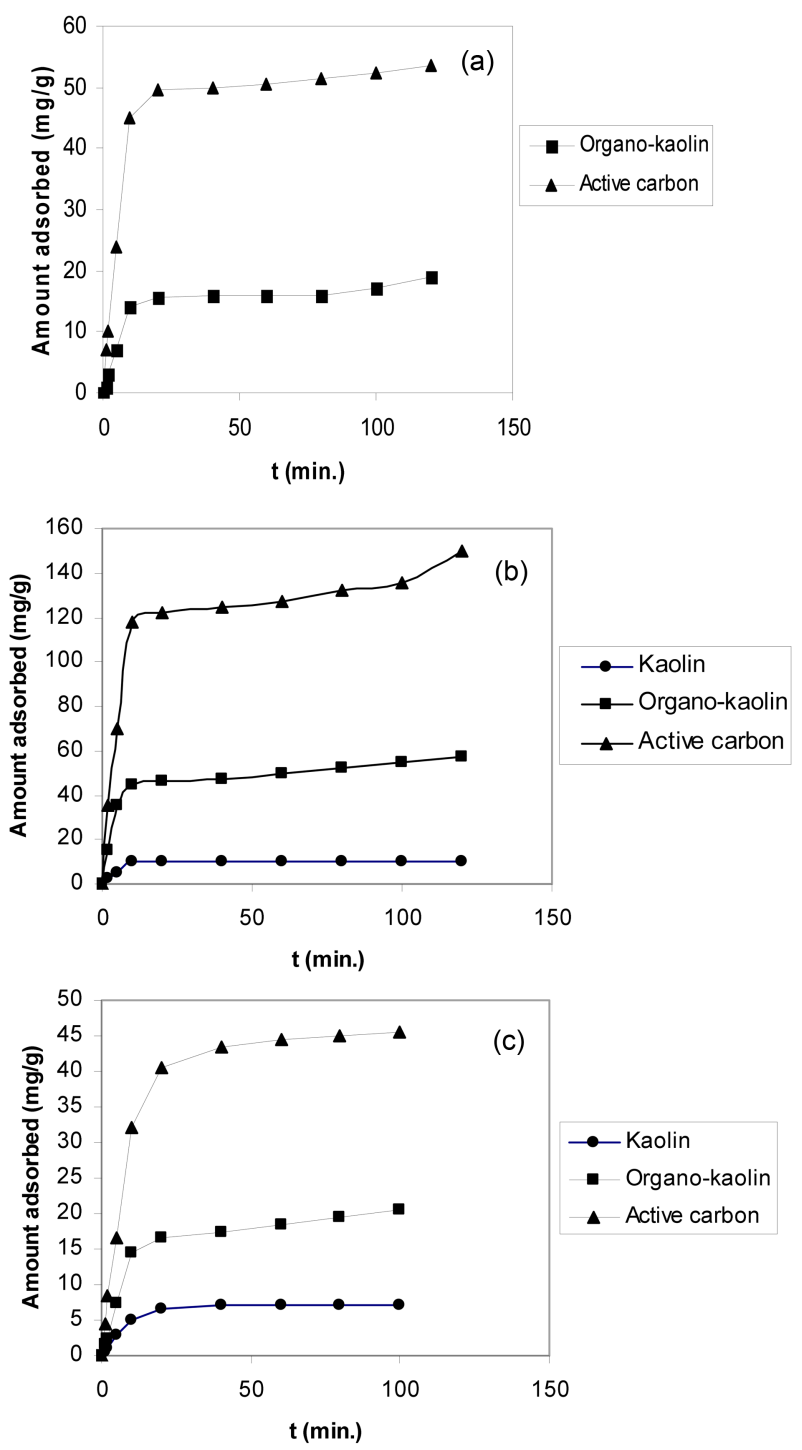

Fig. 4. Kinetic curves of (a) $o$-xylene, (b) Phenol and (c) $\mathrm{Cu}$ (II) sorption at $303 \mathrm{~K}$ onto kaolin, organo-kaolin and activated carbon.

received kaolin showed the lowest adsorption capacities, being lower than the sensitivity limit of the spectroscopy method for $o$-xylene. (2) Modification of kaolin with CTAB considerably increased the sorption capacity compared with as-received kaolin. Fig. 4(a) shows $o$-xylene adsorption of about $15 \mathrm{mg} / \mathrm{g}$ after equilibration for $60 \mathrm{~min}$.

The adsorption of phenol onto organo-clay is about 4-fold higher than the adsorption of the same by as-received kaolin. Modification with CTAB increased also the adsorption of $\mathrm{Cu}$ (II) by about 3 -folds.

(ii) The kinetic curves are in all cases characterizing by an initial steep portion followed by the classical plateau, these plateaux are located at different equilibration time depending on sorbate-sorbent system.

$$
t / q_{t}=1 / k_{2} q_{e}^{2}+t / q_{e}
$$
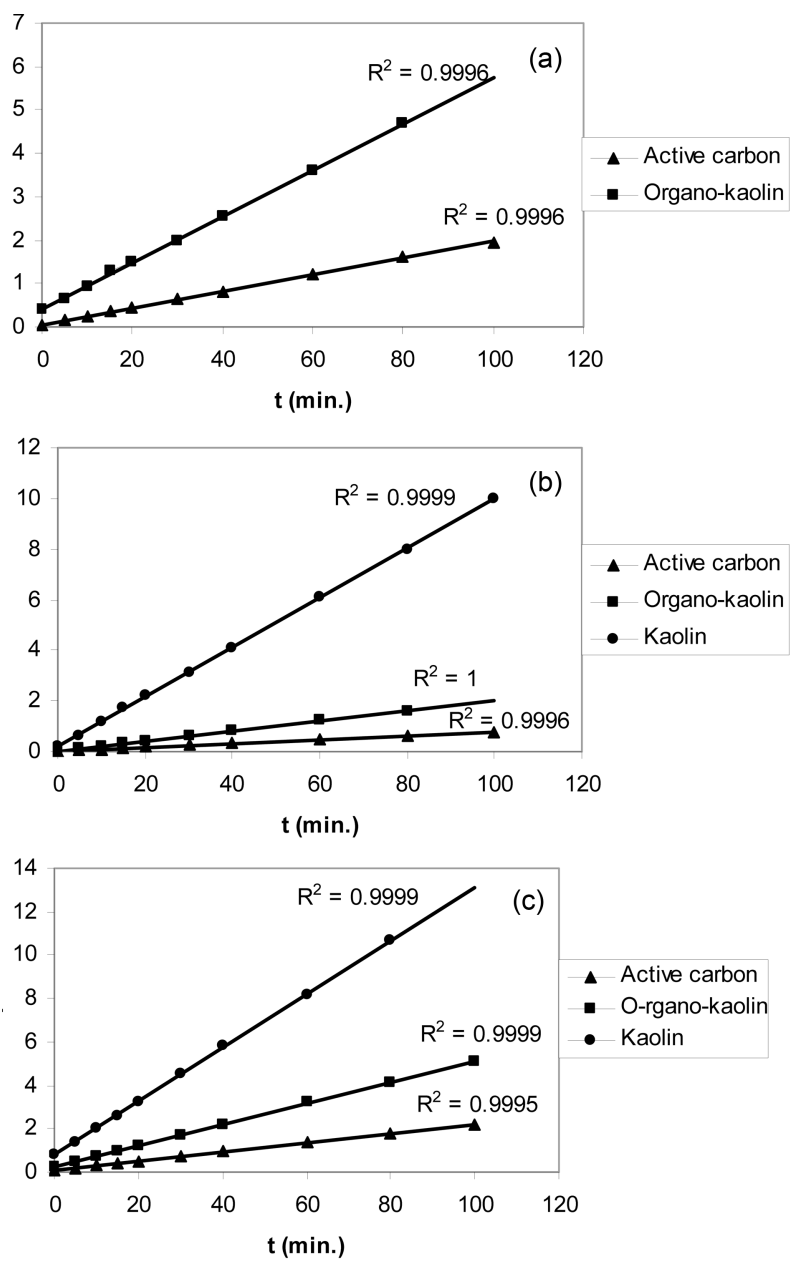

Fig. 5. Linear plot of $\mathrm{t}$ versus $\mathrm{t} / \mathrm{q}_{\mathrm{t}}$ of (a) $o$-xylene, (b) phenol and (c) $\mathrm{Cu}$ (II)sorption at $303 \mathrm{~K}$ onto kaolin, organo-kaolin and active carbon.

Where $\mathrm{q}_{\mathrm{e}}$ and $\mathrm{q}_{\mathrm{t}}$ are the amounts of adsorbate adsorbed at equilibrium and at time $\mathrm{t}$ per unit weight of the sorbent $(\mathrm{mg} /$ g) and $\mathrm{k}_{2}$ is the constant of the pseudo-second order reaction $\left(\mathrm{g} \mathrm{mg}^{-1} \min ^{-1}\right)$. Where, the initial sorption rate constant $\mathrm{h}=\mathrm{k}_{2}$ $q_{e}^{2}\left(\mathrm{mg} \mathrm{g}^{-1} \mathrm{~min}^{-1}\right)$. Figs. 5(a,b\&c) present $\mathrm{t} / \mathrm{q}_{t}$ versus $\mathrm{t}$ for $o-$ xylene, phenol and $\mathrm{Cu}$ (II) ions adsorption onto kaolin, organo-kaolin and activated carbon. $\mathrm{q}_{\mathrm{e}}$ and $\mathrm{k}_{2}$ values as determined for three adsorbate-sorbent systems are listed in Table 2. Included also in this Table are the values of the regression coefficient of each adsorption system. The uptake of sorbate species by sorbents is usually limited by intraparticle diffusion [17] to determine if intraparticle diffusion was the rate-determining step for adsorption, the data in Fig. 5(a,b\&c) were replotted against the square root of time [Fig. 6(a,b\&c)] as suggested by Weber and Morri [18]. According to these authors, if intraparticle diffusion was involved in the sorption process, the uptake of sorbate would vary linearly with the square root of time and furthermore, if intraparticle diffusion were the controlling 
Table 2. Application of Pseudo-second Order and Intraparticle Diffusion to $o$-xylene, Phenol and $\mathrm{Cu}$ (II) Ions Onto Kaolin, Organokaolin and Activated Carbon

\begin{tabular}{cccccccccccccccc}
\hline Sample & \multicolumn{4}{c}{$o$-xylene } & \multicolumn{1}{c}{ Phenol } & \multicolumn{4}{c}{$\mathrm{Cu}(\mathrm{II})$ ions } \\
\hline & $\mathrm{q}_{\mathrm{e}}$ & $\mathrm{k}_{2}$ & $\mathrm{R}^{2}$ & $\mathrm{k}_{\mathrm{d}}$ & $R_{d}^{2}$ & $\mathrm{q}_{\mathrm{e}}$ & $\mathrm{k}_{2}$ & $\mathrm{R}^{2}$ & $\mathrm{k}_{\mathrm{d}}$ & $R_{d}^{2}$ & $\mathrm{q}_{\mathrm{e}}$ & $\mathrm{k}_{2}$ & $\mathrm{R}^{2}$ & $\mathrm{k}_{\mathrm{d}}$ & $R_{d}^{2}$ \\
\hline Kaolin & - & - & - & - & - & 8.2 & 0.0333 & 0.9971 & 4.0 & 0.9999 & 8.19 & 0.0186 & 0.9987 & 1.75 & 0.9812 \\
\hline Organo-kaolin & 18.5 & 0.0073 & 0.9965 & 4.80 & 0.9913 & 14.1 & 0.0017 & 0.9969 & 23.5 & 1.0000 & 20.8 & 0.0093 & 0.9721 & 10.0 & 0.9982 \\
\hline Activated carbon & 53.5 & 0.0035 & 0.9971 & 15.0 & 0.9942 & 50.8 & 0.0009 & 0.9982 & 50.1 & 0.9996 & 50.0 & 0.0027 & 0.9913 & 11.2 & 0.9989 \\
\hline
\end{tabular}

Table 3. Langmuir isotherm constants for adsorption onto kaolin, organo-kaolin and activated carbon at $303 \mathrm{~K}$

\begin{tabular}{ccccccccc}
\hline \multirow{2}{*}{ Sample } & \multicolumn{9}{c}{$o$-xylene } & \multicolumn{3}{c}{ Phenol } & \multicolumn{2}{c}{$\mathrm{Cu}(\mathrm{II})$} \\
\cline { 2 - 11 } & $\mathrm{q}_{\mathrm{m} 1}$ & $\mathrm{q}_{\mathrm{m} 2}$ & $\mathrm{k}_{\mathrm{L} 1}$ & $\mathrm{k}_{\mathrm{L} 2}$ & $\mathrm{q}_{\mathrm{m} 1}$ & $\mathrm{k}_{\mathrm{L}}$ & $\mathrm{q}_{\mathrm{m} 1}$ & $\mathrm{k}_{\mathrm{L}}$ \\
\hline Kaolin & - & - & - & - & 5.1 & 0.0120 & 19.20 & 0.083 \\
\hline Organo-kaolin & 24.2 & 51.8 & 0.0299 & 0.0188 & 91.5 & 0.0081 & 38.50 & 0.294 \\
\hline Active carbon & 91.3 & - & 0.0010 & - & 200.2 & 0.0252 & 123.20 & 0.090 \\
\hline
\end{tabular}
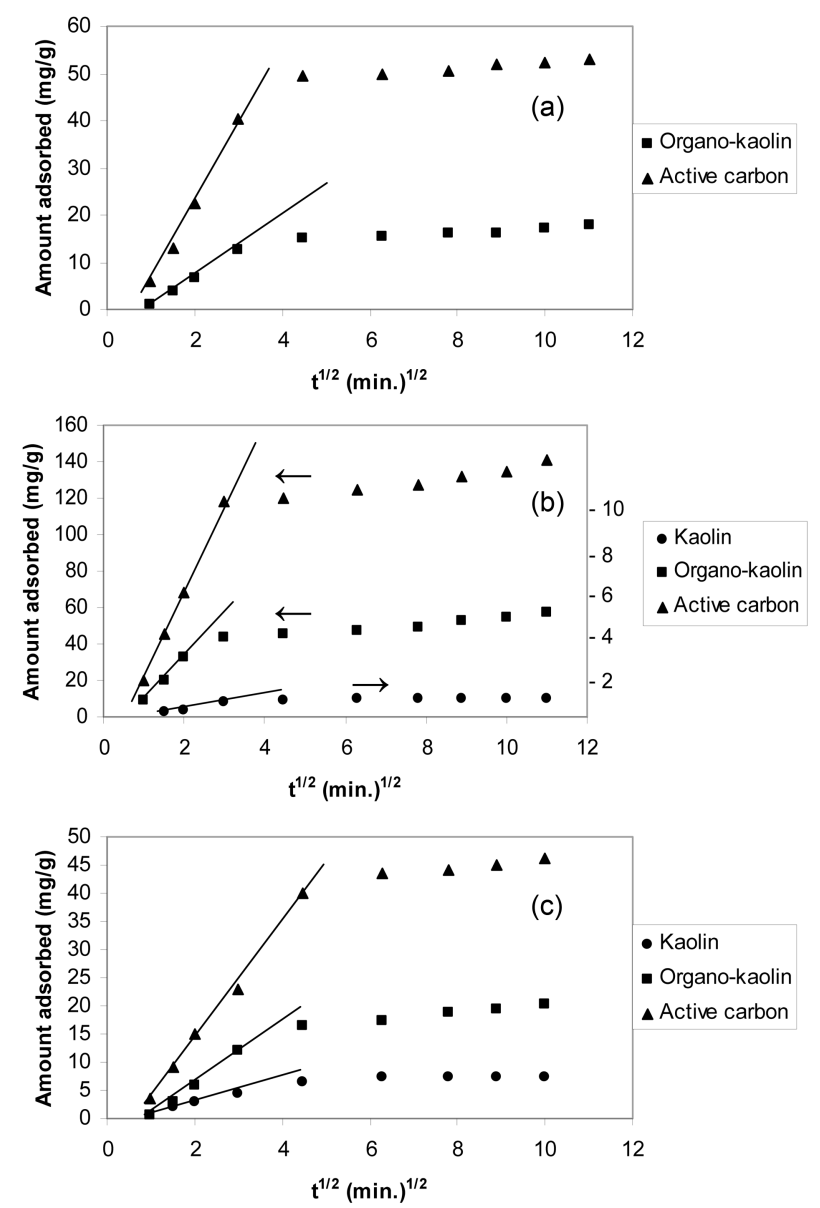

Fig. 6. Plots of (a) $o$-xylene, (b) phenol and (c) $\mathrm{Cu}$ (II) uptake versus the square root of time.

step then this line would pass through the origin [18-20]. As shown in Fig. 6(a,b,\&c), the plots depicted are linear but do not pass through the origin. Hence, although intraparticle diffusion was involved in the adsorption process it was not the sole limiting factor [21]. Evidently, the linear plots of organo-clay and activated carbon are characterized by large slopes than those than of kaolin. This indicates that adsorption on these sorbent is more controlled by intraparticle diffusion. Values of intraparticle diffusion constant $\mathrm{k}_{\mathrm{d}}\left(\mathrm{mg} / \mathrm{g} \min ^{0.5}\right)$ and the regression coefficients for the intraparticle diffusion model $\left(R_{d}^{2}\right)$ are also listed in the Table 2.

Table 2 reveals that sorption of $o$-xylene, phenol and $\mathrm{Cu}$ (II) ions complies very well with pseudo-second order reaction and an activated sorption mechanism as indicated by the high values of $\mathrm{R}^{2}$. This may be taken as evidence that the rate of the reaction depends on both the sorbent and sorbate concentration [22]. The values of $k_{2}$ decreased and $k_{d}$ increase with the increase of the amount of solute sorbed.

\subsection{Equilibrium adsorption isotherm}

The Langmuir isotherm model was fitted to the experimental adsorption equilibrium data. This isotherm model may be represented by the equation

$$
q=\frac{q_{m} k c}{1-k c}
$$

Where $\mathrm{c}$ is the equilibrium solute concentration $(\mathrm{mg} / \mathrm{l}), \mathrm{k}$ is the constant of the Langmuir isotherm $(1 / \mathrm{mg}), \mathrm{q}$ is the equilibrium uptake of the adsorbate onto the sorbent $(\mathrm{mg} / \mathrm{g}$ ) and $\mathrm{q}_{\mathrm{m}}$ is the maximium uptake of solute adsorbed onto the sorbent $(\mathrm{mg} / \mathrm{g})$. The isotherm constants were estimated and are given in Table 3.

The Langmuir isotherms Fig. 7(a-c) fitted the adsorption equilibrium data for phenol and $\mathrm{Cu}$ (II) ion onto kaolin, organo-kaolin and activated carbon. The equilibrium adsorption isotherms of $o$-xylene onto organo-kaolin and activated carbon fitted also Langmuir equation. The adsorption of $o$-xylene onto kaolin was very low to be measured. It remains now to point out that $o$-xylene sorption by organo-kaolin exhibited Langmirian isotherm but with two plateaux indicating bimodal sorption classified by Giles 

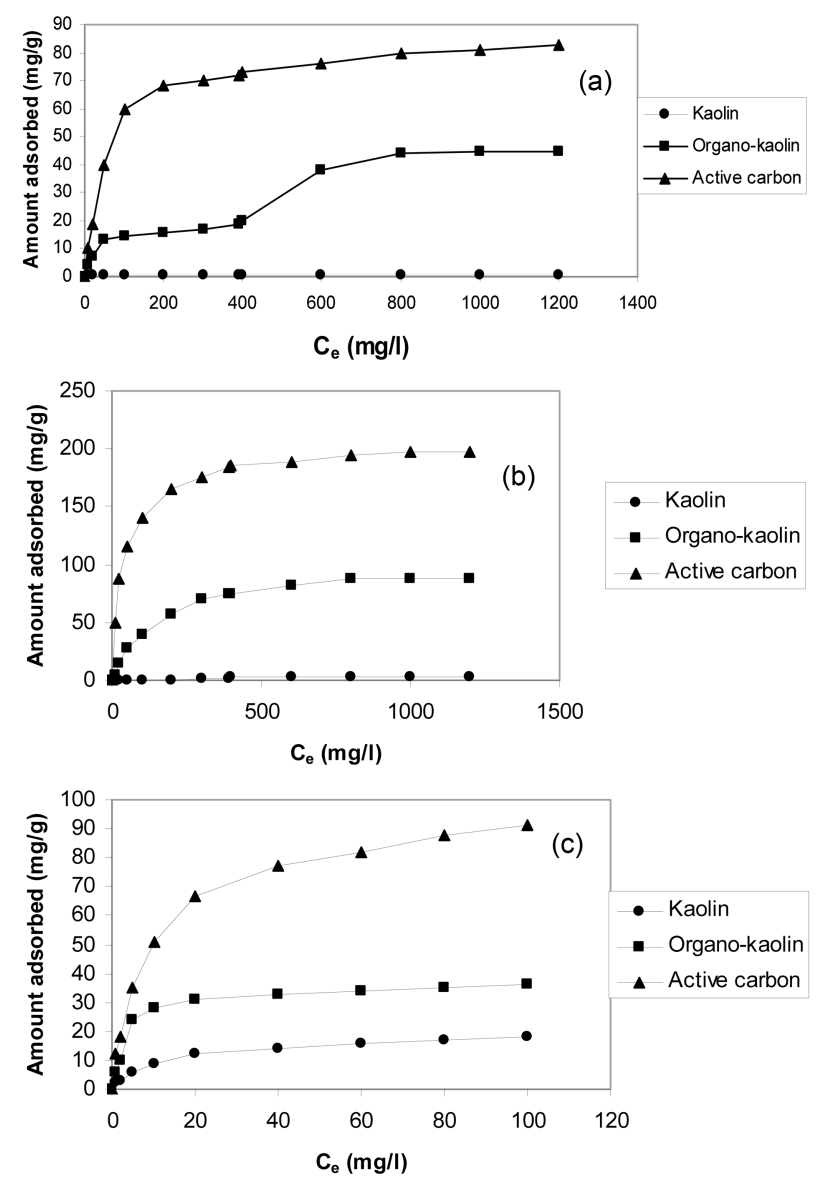

Fig. 7. Equilibrium adsorption isotherms of (a) $o$-xylene, (b) Phenol and (c) $\mathrm{Cu}$ (II) $303 \mathrm{~K}$ and pH 6 onto (O) kaolin, (ם) organo-kaolin and $(\mathbf{\Delta})$ activated carbon.

\section{[23] as (Langmuir subgroup 4) adsorption.}

The adsorption equilibrium data for $o$-xylene by organokaolin can be represented reasonably well by the modified bimodal Langmuir isotherm [24]. Equations 3 and 4 describe this particular isotherm.

$$
\begin{aligned}
& q=\frac{q_{m 1} k_{1} c}{1+k_{1} c} \quad \mathrm{c} \leq \mathrm{c}_{\mathrm{s}} \\
& q=\frac{q_{m 1} k_{1} c}{1+k_{1} c}+\frac{q_{m 2} k_{2}\left(c-c_{s}\right)}{1+k_{2}\left(c-c_{s}\right)} \quad \mathrm{c}>\mathrm{c}_{\mathrm{s}}
\end{aligned}
$$

Where $\mathrm{c}_{\mathrm{s}}$ is the equilibrium concentration of $o$-xylene at which the first step ends, the quantity $\mathrm{c}_{\mathrm{s}}$ was estimated to be $400 \mathrm{mg} / \mathrm{l}$. The values of Langmuir constants are listed in Table 3.

\subsection{Adsorption of o-xylene}

Modification of the mineral surface of natural kaolin by CTAB had a major affect on the adsorption capacity of the resulting organo-kaolin. The experimental adsorption equilibrium data for $\boldsymbol{o}$-xylene onto kaolin, organo-kaolin and activated carbon are depicted in Fig. 7(a). o-Xylene was adsorbed to a considerable extent onto the organo-kaolin and activated carbon but not onto kaolin. $o$-Xylene is hydrophobic and ionizable existing as the protonated or the deprotonated species (an anion) depending on the solution $\mathrm{pH}$. According to the authors [24], deprotonated species exist at $\mathrm{pH}$ greater than 4 , whereas, the protonated species is predominant when the $\mathrm{pH}$ is less than 4 . In the present work, the adsorption equilibrium data were determined at a $\mathrm{pH}$ value of 6 at which $o$-xylene is mainly in the deprotonated form. These species were mainly adsorbed on the organophilic part of the organo-kaolin via partitioning mechanism [5].

The adsorption isotherm of $o$-xylene on organo-kaolin is shown in Fig. 7(a); the isotherm was type $\mathrm{L}$ in the Giles classification, indicating that adsorption occurred on the surfaces and in the micropores of the organo-kaolin. At an $o-$ xylene loading less than $20 \mathrm{mg} / \mathrm{g}$, the $o$-xylene molecule was adsorbed onto the organo-kaolin via interactions between the surfactant molecule and $o$-xylene molecule. Beyond $20 \mathrm{mg} / \mathrm{g}$ loading a second layer of $o$-xylene may be adsorbed onto the already adsorbed $o$-xylene layer, in agreement thus with previously reported data [25,28]. The authors [29] have suggested that such behaviour is due to both polar and hydrophobic interactions.

The adsorption isotherms for $o$-xylene onto kaolin, organo-kaolin and activated carbon are compared in Fig. 7(a). Table 3 lists the Langmiur adsorption properties of different investigated adsorbents at $303 \mathrm{~K}$. It is seen from Fig. 7(a) that the adsorption capacity of activated carbon was greater than that of the organo-kaolin. Indeed, when the maximum mass of $o$-xylene adsorbed was compared, it was found that the adsorption capacity of activated carbon was 1.2 times greater than that of the organo-kaolin. Since the surface of kaolin is hydrophilic, $o$-xylene was not adsorbed onto this adsorbent and no organophilic interactions occurred between the kaolin surface and the $o$-xylene molecule.

\subsection{Adsorption of Phenol}

The experimental adsorption equilibrium data for phenol onto kaolin, as well as organo-kaolin and activated carbon are depicted in Fig. 7(b). Whereas, phenol was only slightly adsorbed onto the kaolin. The mass of phenol adsorbed onto the organo-kaolin was on average 18 times greater than that onto the natural kaolin. The value of the acid dissociation constant for phenol $\left(\mathrm{pk}_{\mathrm{a}}=9.96\right)$ indicates that phenol is protonated at $\mathrm{pH}$ values below 9.96 and deprotonated as the phenolate anion at $\mathrm{pH}$ values greater than 9.96 [12]. The experimental adsorption data were obtained at $\mathrm{pH}=6$ when the phenol molecule was mainly present as the protonated species. Thus, phenol was mainly adsorbed onto the organoclay via hydrophobic and organophilic interactions [30]. 
Fig. 7(b) shows that the experimental equilibrium adsorption data for phenol onto the organo-kaolin exhibited linear behaviour up to concentration of less than $200 \mathrm{mg} / \mathrm{l}$. Such linear behaviour has been reported by other authors $[11,12,22,31]$ and in all cases, linear behaviour was observed at equilibrium phenol concentration less than $200 \mathrm{mg} / \mathrm{l}$, with the mass of phenol adsorbed being less than $50 \mathrm{mg} / \mathrm{g}$. This linear behaviour may be attributed to the presence of alkyl chain cations which form an organic phase onto organokaolin on which phenol molecules can be sorbed. Such sorption occurs via a partitioning mechanism because of the distribution of phenol molecules between the aqueous phase and the organic phase [25].

Fig. 7(b) shows that activated carbon exhibited the highest phenol adsorption capacity. Thus at an equilibrium phenol concentration of $100 \mathrm{mg} / \mathrm{L}$, the adsorption capacity of activated carbon for phenol was 3.7 times higher than that of organo-clay.

\subsection{Adsorption of $\mathrm{Cu}(\mathrm{II})$ ions}

The equilibrium adsorption isotherms of $\mathrm{Cu}$ (II) at $303 \mathrm{~K}$ and $\mathrm{pH} 6$ onto kaolin,organo-kaolin and activated carbon are depicted in Fig. 7(c).

Adsorption of metal ions on different adsorbents can be attributed to two terms, intrinsic adsorption and coulombic interaction. Coulombic term results from the electro-static energy of interactions between the adsorbent and adsorbate. The charges on substrates as well as softness or hardness of the charges on both sides are mostly responsible for the intensity of the interaction, or amount of adsorption. Coulombic interaction can be reflected from adsorption of cationic species versus anionic species on adsorbents.

The intrinsic adsorption of the materials is determined by their surface areas, which can be observed by the effect of modification of the kaolin surface and activation of peanutshells. Both factors may interact with each other during the course of adsorption of chemicals in aqueous solution as well.

The adsorption isotherms of $\mathrm{Cu}$ (II) ions onto the sorbents investigated are shown in Fig. 7(c). The isotherms are characterized by steep initial portions at low equilibrium concentration followed by a tendency to saturation at high equilibrium concentration, i.e. of Langmuirian type. The Langmuir equation was applied and the maximum sorption capacities were calculated and listed in Table 3.

The maximum adsorption capacity of $\mathrm{Cu}$ (II) was calculated to be $123.2 \mathrm{mg} / \mathrm{g}$ for activated carbon whereas that of as-received kaolin amounts to $19.2 \mathrm{mg} / \mathrm{g}$. Modification with CTAB to have organo-kaolin is adsorbed with 2-fold increase in $\mathrm{Cu}$ (II) adsorption capacity.

In case of organic kaolin, the adsorbed CTAB molecules cover large fraction of the kaolin surface rendering it positively charged. At the interface, there is always an unequal distribution of electric charges between the two phases. The unequal distribution causes one side of the interface to acquire a net charge of a particular sign and the other side to acquire a net charge of the opposite sign giving rise to a potential across the interface and the so called electric double layer. Of course, since overall electrical neutrality must be balanced by an exactly equivalent charge of opposite sign on the other side of the interface. However, the distribution of the neutralizing charges (counter ions) in the solution is still of conflict.

The uptake of $\mathrm{Cu}(\mathrm{II})$ on CTAB covered kaolin surface may proceed via a mechanism other than cation-exchange dominating in the case of kaolin. The positive charges on nitrogens of adsorbed CTAB molecules are weakened by the three attached electron-donating methyl groups. This favors the electrostatic attraction of the counter ions in the electric double layer $\left(\mathrm{Br}^{-}\right)$with $\mathrm{Cu}(\mathrm{II})$ ion solution via ion pairing [27] according to the following scheme. The pore widening associated with

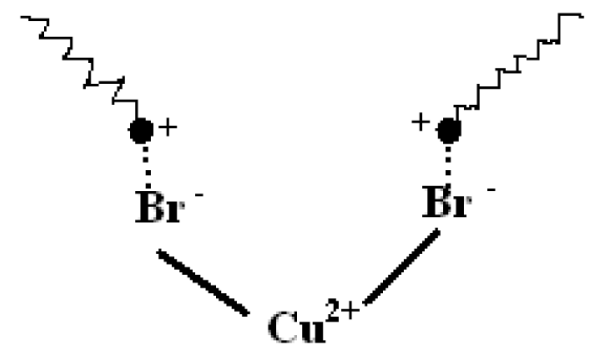

CTAB adsorption probably increases the access of copper solution to successive layers which were beyond reach before pore widening. Of course, the removal of $\mathrm{Cu}$ (II) on the fraction of the surface uncovered with CTAB still proceeds via exchange with the cations existing on kaolin surface such as $\mathrm{Na}^{+}$.

\subsection{Nature of the adsorbate molecule}

The adsorption of a solute onto a porous solid is highly dependent on the interactions between the solute molecule and the solid surface. Hence the nature of the solute plays a very important role in determining the adsorption capacity of organo-kaolin. The amount adsorbed and the equilibrium concentrations are expressed as $\mathrm{mmol} / \mathrm{g}$ and $\mathrm{mmol} / \mathrm{L}$, respectively. This expression may give more information on the sorbate-sorbent interactions. The organo-kaolin is selected from the investigated adsorbents.

Fig. 8 shows the equilibrium adsorption isotherms of $o$ xylene, phenol and $\mathrm{Cu}(\mathrm{II})$ onto organo-kaolin. Fig. 8 depicts that at equilibrium concentration $<1.5 \mathrm{mmol} / \mathrm{L}, \mathrm{Cu}(\mathrm{II})$ exhibited the highest adsorption capacity onto organo-kaolin whereas $o$-xylene exhibited the lowest adsorption capacity on the same sorbent. This may be ascribed to the different mechanism involved in the adsorption of these adsorbents 


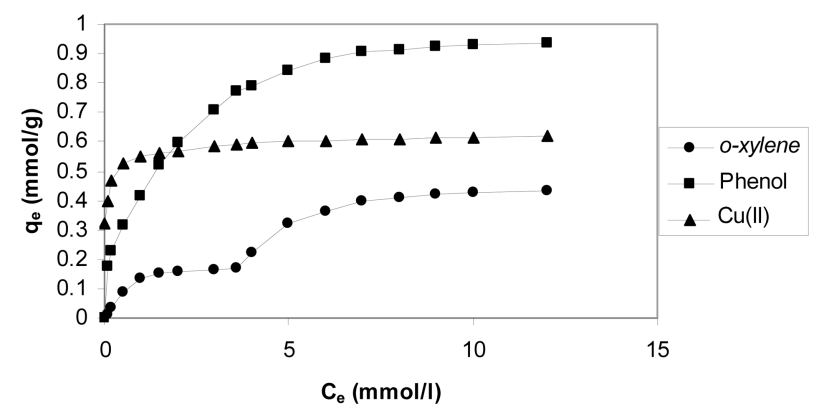

Fig. 8. Adsorption isotherms for $(\mathbf{\bullet}) o$-xylene, $(\boldsymbol{\square})$ phenol and $(\boldsymbol{\Delta})$ $\mathrm{Cu}(\mathrm{II})$ at $\mathrm{pH}$ value of 6 onto the organo-kaolin at $303 \mathrm{~K}$.

onto organo-kaolin. $\mathrm{Cu}(\mathrm{II})$ adsorption may involve electrostatic interaction with negatively charged surface of the organokaolin and possibly via complex formation with the surfactant. $o$-Xylene on the other hand may adsorb in the first layer via the organophilic-organophilic interaction. $O$ Xylene is springly soluble in water, i.e. hydrophobic and consequently its interaction with the organophilic sites on the sorbent surface is expected. As to the adsorption of $o$-xylene in the second layer, adsorbate-adsrbate interaction probably controls this adsorption. The adsorption of phenol may involve hydrophilic-hydrophilic interaction. The organokaolin has hydrophilic sites which can interact with phenol which is a hydrophilic material soluble in water.

It remains now to point out that at equilibrium concentration of the adsorbate $>2.0 \mathrm{mmol} / \mathrm{L}$, phenol adsorption exhibited higher adsorption than $\mathrm{Cu}$ (II) on organo-kaolin. The adsorption isotherm of $\mathrm{Cu}(\mathrm{II})$ exhibits a well developed plateau through which no significant increase in adsorption is observed with the increase of the equilibrium concentration. The complete coverage of sites forming electrostatic interaction with $\mathrm{Cu}$ (II) may stand behind this behavior.

\section{Conclusions}

The adsorption of $o$-xylene, phenol and $\mathrm{Cu}(\mathrm{II})$ at $\mathrm{pH} 6$ and $303 \mathrm{~K}$ onto kaolin, organo-kaolin and activated carbon was investigated for all the adsorbates, activated carbon exhibited the highest capacity whereas kaolin showed the lowest.

Modification of kaolin by a cationic surfactant (CTAB) changed the its surface properties and increase its adsorption capacity towards phenol, $o$-xylene and $\mathrm{Cu}(\mathrm{II})$, from their aqueous solutions.

The adsorption systems investigated are controlled by interaparticle diffusion and followed pseudo-second order kinetic. The adsorption isotherms of all the sorbent-sorbate system investigated are of Langmuirian type and the maximum adsorption capacities were calculated by the application of the Langmuir equation.

The adsorption of $\mathrm{Cu}(\mathrm{II})$ onto organo-kaolin proceeds via electrostatic interaction and complex formation. Adsorption of ortho-xylene onto organo-kaolin exhibited by layers, the adsorption in the first proceeds via organophilic-organophilic interaction and in the second layer via sorbate-sorbate interaction. Phenol adsorption involved hydrophilichydrophilic interaction.

\section{References}

[1] Mortland, M. M.; Shaobal, S.; Boyd, S. A. Clays Clay Miner. 1986, 34, 581.

[2] Ceyhan, O.; Guler, H.; Guler, R. Adsorp. Sci. Technol. 1999, 17, 469.

[3] Smith, J. A.; Jaffe, P. R.; Chiou, C. T. Environ. Sci. Technol. 1990, 24, 1167.

[4] Xu, S.; boyd, S. A. Environ. Sci. Technol. 1995, 29, 3022.

[5] Shen, Y. H. Colloids Surf. A 2004, 232, 143.

[6] Sheng, G.; Xu, S.; Boyd, S. A. Environ. Sci. Technol. 1996, 30, 1553.

[7] Boyd, S. A.; Mortland, M. M.; Chiou, C. T. Soil Sci. Soc. Am. J. 1988, 52, 652 .

[8] Boyd, S. A.; Shaobai, S.; Lee, J. F.; Mortland, M.M. Clays Clay Miner. 1988, 36, 125.

[9] Zhu, L.; Li, Y.; Zhang, J. Environ. Sci. Technol. 1997, 31, 1407.

[10] Zhu, L.; Ren, X.; Yu, S. Environ. Sci. Technol. 1998, 32, 3374.

[11] Baskralingam, P.; Pulikesi, M.; Elango, D.; Ramamurti, V.; Sivanesan, S. J. Hazard. Mater. 2006, 128, 138.

[12] Huh, J.K.; Song, D.I; Jeon, Y.W. Sep. Sci. Technol. 2000, $35,243$.

[13] Stapleton, M.G.; Sparks, D.L.; Dentel, S.K. Environ. Sci. Technol. 1994, 28, 2330.

[14] Wang, C. C.; Juang, L.C.; Lee, C. K.; Hsu, T.C.; Lee, J. F.; Chao, H. P. J. Colloid Interface Sci. 2004, 228, 27.

[15] El-Geundi, M. S.; Farrag, T. E.; Abd El-Ghany, H. M. Adsorp. Sci. \& Technol. 2005, 23, 437.

[16] Bhuttacharyya, K. G.; Gupta, S. S. Sep. Purif. Technol. 2006, 50, 388.

[17] Ajmal, M.; Khan, A.; Ahmade, A. Water Res. 1998, 32, 3085.

[18] Weber, W. J.; Morris, J. C. J. Sanit. Eng. Div. Am. Soc. C.V. Eng. 1963, 89, 31.

[19] Ozcan, A.; Sahin, M.; Ozcan, A. S. Adsorp. Sci. Tehnol. 2005, 23, 323.

[20] Wang, X.S.; Qin, Y.; Li, Z.F. Sep. Sci. Technol. 2006, 41, 747.

[21] Poots, V.; Mckay, G.; Healy, J. Water Res. 1976, 10, 1061.

[22] Xue-Song, W.; Jin, W.; Cheng, S. Adsorp. Sci. Technol. 2006, 6, 517.

[23] Giles, C. H.; Mac Ewan, T. H.; Nakhwa, S. N.; Smith, D. J. Chem. Soc. 1960, 3973.

[24] Guo, Z.; Zheng, S.; Zheng, Z.; Jiang, F.; Hu, W.; Ni, L. 
Water Res. 2005, 39, 1174.

[25] Andini, S.; Cioffi, R.; Montagnaro, F.; Pisciotta, F.; Santero, L. Appl. Clay Sci. 2006, 31, 126.

[26] Milton, J. R. "Surfactants and Interfacial Phenomena", John Wiley \& Sons, New York, 1988, 35.

[27] Rupprecht, H.; Liebl, H. Kolloid, Z.Z. Polym. 1972, 250, 719.

[28] Carrizosa, M. J.; Hermosin, M.; Koskinen, W. C.; Corneja,
J. Soil Sci. Soc. Am. J. 2003, 67, 511.

[29] Sheng, G.; Boyed, A. Clays Clay Miner. 2000, 48, 43.

[30] Araceli, J.-A.; Roberto, L.-R.; Erika, P.-O.; Antonio, A.-P.; Rosa Maria, G.-C.; Javita, M.-B. Adsorp. Science \& Technol. 2006, 24, 687.

[31] Rawajfih, Z.; Nsour, N. J. colloid Interface Sci. 2006, 298, 39. 